Abstract

\title{
Tyrosinase Immobilization in Multi Walled Carbon Nanotube and Gold Nanowires Matrice for Catechol Detection ${ }^{\dagger}$
}

\author{
Sevinc Kurbanoglu * and Sibel A. Ozkan \\ Faculty of Pharmacy, Department of Analytical Chemistry, Ankara University, 06100 Tandogan, Ankara, \\ Turkey; ozkan@pharmacy.ankara.edu.tr \\ * Correspondence: skurbanoglu@gmail.com \\ + Presented at the 5th International Symposium on Sensor Science (I3S 2017), Barcelona, Spain, \\ 27-29 September 2017.
}

Published: 19 December 2017

Catechol biosensing with a low limit of detection is an essential topic for researches due to catechol's easily oxidizable and easy to follow amperometrically properties. Screen-printed electrodes are disposable devices that find widespread use in the field, including analytical chemistry, drug control, clinical and environmental analysis [1,2]. In this work, a novel catechol biosensing platform is suggested with the synergetic effect between multi walled carbon nanotube, gold nanowires and tyrosinase enzyme. Tyrosinase is a multifunctional copper-containing enzyme that catalyzes two distinct reactions of melanin synthesis using catechol, which is a well-known substrate of Tyrosinase. All the parameters affecting the biosensing response are optimized and the method is further validated. Using the synergetic effects between multi walled carbon nanotube and gold nanowires, sensitive catechol determination was found with LOD and values 0.027 and 0.080 $\mu \mathrm{M}$, respectively.

\section{References}

1. Kurbanoglu, S.; Rivas, L.; Ozkan, S.A. Merkoçi, A. Electrochemically reduced graphene and iridium oxide nanoparticles for inhibition-based angiotensin-converting enzyme inhibitor detection. Biosens. Bioelectron. 2017, 88, 122.

2. Kurbanoglu, S.; Ozkan, S.A.; Merkoçi, A. Nanomaterials-based enzyme electrochemical biosensors operating through inhibition for biosensing applications. Biosens. Bioelectron. 2017, 89, 886-898.

(C) 2017 by the authors. Licensee MDPI, Basel, Switzerland. This article is an open access article distributed under the terms and conditions of the Creative Commons Attribution (CC BY) license (http://creativecommons.org/licenses/by/4.0/). 